\title{
Smartphones: An Effective Aid in Teaching- Learning of English Language
}

\author{
Dr. Sandip P. Gawate ${ }^{1}$, Mr. Ajitrao Babasaheb Jadhav²
}

${ }^{1}$ MA (Eng.), M.Phil. (Eng.), Ph.D. (Eng.), SET (Eng.), Asst. Professor of English, Jayawantrao Sawant College of Commerce and Science, Hadapsar, Pune-411028, India

${ }^{2}$ M.A. (Eng.), B.Ed. PhD (Pursuing), Sr. Lecturer in English, Jayawantrao Sawant Polytechnic, Hadapsar, Pune, India

\begin{abstract}
This research paper covers the utilization of smart phones effectively in the teaching-learning process of English at a variety of levels. In this world of technology use of technological innovations and electronic gadgets have become the inseparable parts of our life. These technological innovations have brought enormous change in everybody's life. Smart phone is, being the handy electronic gadget, one of the outstanding inventions of technology. The concept of ICT based education has changed entire teaching-learning process. Teachers as well as students are techno-savvy and believe in learning through the electronic gadgets. As the students have knowhow of the electronic gadgets, the teachers also need to employ such devices in their teaching process. Day by day the sacred field of education is being developed and modified with the help of technological progress all over the world. It also saves time of both the teachers and the students. This paper specifically covers the ways of smartphones implementation in the teaching-learning process. Thus, the present paper is a modest attempt and the result of the continual research and use of smartphones in teaching-learning process of English language.
\end{abstract}

Keywords - technology, Smartphones, ICT based education, electronic gadgets, teaching-learning.

\section{INTRODUCTION}

Technological growth is inevitable for every nation to become developed. Such growth is essential in all the major and minor sectors also. The concept of 'Digital Literacy' denotes the practical knowledge of the electronic gadgets. Without 'digital literacy' one cannot become a successful teacher as well as student. A Smartphone is one of the crucial technical inventions. It must be utilized in all the sectors and specifically in the field of education constructively. The researcher, being in the field of teaching more than a decade, has been using smartphone effectively. The smartphones can be used as an asset rather than a risk in the classroom. It has been observed that so many teachers disallow the students for using the smartphones. Both the teachers and the students can utilize it efficiently in the teaching-learning process. Surely use of smartphones is one of the innovative and novel educational trends. Smartphones can be executed in a multitude ways in the teaching-learning process of English language. In brief, the Smartphones can foster the process of teachinglearning in better fashion.

\section{USAGES OF SMARTPHONES IN TEACHING-LEARNING PROCESS OF ENGLISH}

The below-given are some of the prominent usages of the smartphones in teaching-learning process of English. They are beneficial in learning and improving listening, speaking, reading, and writing skills (LSRW) of English.

\section{Enriching Vocabulary}

Vocabulary is the base of every language and the English language learners have to learn the vocabulary of the target language properly. Teacher can elucidate how the smartphones are useful to learn vocabulary. The demonstrations can be given to the students in the classroom. Offline smartphone based applications can be utilized to teach and learn vocabulary. Learning vocabulary of the target language means knowing the aspects of the word/s like spelling/s, pronunciation/s, category of the word/s, synonyms and antonyms, and usages of the word/s. As there are many dictionaries available online and these can be referred to online. It needs internet connection. Thus improvement of vocabulary is possible with the help of it. Teachers can allow the students to search the meanings of the words on smartphones. 


\section{Dictionary (Mono-lingual and Bi-lingual)}

Many online and offline dictionaries are available in the smartphones. Online dictionaries require internet and offline dictionaries can be installed in the smartphones. Offline dictionaries become available through 'Google Play Store'. Such dictionaries are useful for the students. The students can enter the word in the search tab and just on one click can see the meaning of the word. It becomes irritating for both the teachers and the students to take the hard copy of the dictionary in the class. It also time consuming activity to search a word in the hard copy of a dictionary. On the other hand, searching a word in smartphone based dictionary is time saving. The student needs to open the dictionary and enter the word only. All the aspects related to the word come like pronunciation, word category, different meanings under different numbers, usages, etc. Dictionaries like Oxford, Cambridge, Webster, etc. are available easily.

It is expected to use monolingual dictionaries rather than bi-lingual dictionaries. Sometimes, it becomes necessary to use bi-lingual dictionary. It depends upon the level and the needs of the learner. The Indians, being the non-native users of English language, have to come deliberately in the contact of English to learn it.

\section{Recording (Audio and Video)}

All the smartphones have the facility of voice recording as well as video recording just on certain clicks. The students can shoot the lecture of the teacher to refer to in future. The videos available on Internet can also be downloaded and saved in the smartphone as it has internal and external memory to store such files. By watching such videos one can teach as well as learn language on one's own. Besides, audio files can be saved and listened to them repetitively. It helps to develop listening and speaking skills of the learner. Lectures of subject matter experts, well-known speeches, conversations, topic wise discussions, and many more can be recorded in video as well as audio forms for future reference.

\section{Mobile Applications to teach and learn English}

It is really fantastic to utilize a variety of mobile applications to learn English at one's own pace. Most of the apps are free of cost and need to be installed only. In smartphones such apps can be played without problems. Some of the examples of such applications are

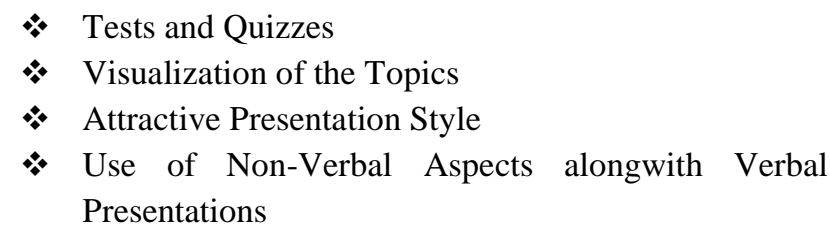

* Sharing Ideas, Notes, Articles, etc.

* Simulations

* Games Based Teaching and Learning

* Translator

* Ample Resources for English Language

* Document Scanner

* Reference

* Virtual Library

* Podcasts

* Screen Cast or Screen Mirror

* Evaluation (Using Performance Based Analytical Software/s)

* Academic Blogs

\section{Online Resources}

All the smartphones are handy and one can access internet on it as smartphones contain inbuilt internet set up. Many online resources can be used to learn English. It will really be a great assistance to the teachers and the students also. Due to internet the world got the virtual proximity and one can access all the resources online. A number of resources can be accessed free or paid too. But in most of the cases they are free to use. By using such resources the students can learn many aspects of English language. In this exercise the teachers can direct the students and point out them the standard online resources to use while learning English. So many online tests are also available online. They can be solved online and auto-generated feedback can be observed with the statistics and proper explanations to evaluate the students. Thus, it supports to learn English in very easy manner. Youtube is also an online resource that can be used to find out quality subject experts. A number of educational websites are also available.

\section{Applications to Create Own Presentations}

A number applications are available in Smartphones to create own presentations. Microsoft office can also be downloaded and work can be done. It will help the students the data provided by the teachers can be opened with the help of these applications. As an instance PowerPoint Presentation can be opened and referred to at anytime and anywhere.

\section{SMARTPHONES AND PRESENT SCENARIO OF EDUCATION}

The smartphones are affordable to all the students. It is apparent that near about ninety percent students have smartphones and they can make effective use of such gadgets nicely. Even the students from rural area have smartphones. The concept of 'Digital India' is a kind of trigger to boost up the use of technology at the bottom level in all the sectors. Besides, use of the smartphones in 
education, particularly in teaching-learning of English, supports paperless movement. As a result it helps to balance nature by saving trees at broader level.

It is also important to know there may be distractions because of smartphones in the class. But it can be controlled by the teacher. It can be done by keeping the students engaged in the learning activities. Simultaneously the learners must be educated to look at the smartphone as a tool of education rather than a device for entertainment only.

\section{CONCLUSION}

In the field of teaching-learning of English many methods have been implemented by considering their scope and limitations. But this field requires trials of different methods, policies and approaches. Definitely there are the advantages as well as disadvantages of using smartphones but we have to employ them constructively in classroom situations. If smartphones are used effectively in teachinglearning process of English language, it is the real practice and knowhow to use ICT (Information and Communications Technology) in education sector. To sum up this, the present paper is a novel attempt to find out a variety of uses of smartphones in teaching-learning of English language.

\section{REFERENCES}

[1] Anita Rosen, E-Learning 2.0: Proven Practices and Emerging Technologies to Achieve Real Results, AMCOM, New York, 2009, Print.

[2] Andrew Middlton, Smart Learning: Teaching and Learning with Smartphones and Tablets, Sheffield City Polytechnic, Department of Education Services, 2015. Print.

[3] K. B. Powar, Murli D. Tiwari, H. P. Dikshit, et al, ICT enabled education, Association of Indian Universities, 2002. Print.

[4] Anjali Khirwadkar, K. Pushpanadham, Information and Communication Technology in Education: Interactive Multi-media Instructional Strategies for Teaching-Learning Process, Sarup \& Sons, New Delhi, I Ed., 2005. Print.

[5] Chauhan S. S., Innovations in Teaching Learning Process, Vikas Publishing House Pvt Limited, 2009. Print.

[6] Retta Guy, The Evolution of Mobile Teaching and Learning, Informing Science Press, California, USA. 2009. Print. 